\title{
Quali/quantitative research on herbal supplements containing black elder (Sambucus nigra L.) fruits
}

\author{
Etil GÜZELMERIÇ ${ }^{1 *}$ (D), Cansel ÇELİK ${ }^{1}$ (D) Nisa Beril ŞEN ${ }^{1}$ (D) Mehmet Ali OÇKUN ${ }^{2}$ (D), \\ Erdem YEŞILADA 1
}

1 Department of Pharmacognosy, Faculty of Pharmacy, Yeditepe University, İstanbul, Turkey.

2 Faculty of Pharmacy, Yeditepe University, İstanbul, Turkey.

* Corresponding Author. E-mail: etil.ariburnu@yeditepe.edu.tr (E.G.); Tel. +90-216-578 0000.

Received: 11 December 2020 / Revised: 12 March 2021/ Accepted: 26 March 2021

\begin{abstract}
Black elder (Sambucus nigra L.), rich in phenolics, is used as antiviral, especially to treat common cold and flu. The flower of black elder has been approved by German Commission E and ESCOP for its mentioned usage, and in several pharmacopoeias, its qualification parameters were described. However, its fruits with a similar use as the flowers have not been considered by the pharmacopoeias. Even so, the number of black elder fruit supplements marketing with different brands is increasing steadily. This study aimed to evaluate the availability and concentrations of marker components (chlorogenic acid, rutin, and isoquercitrin) in herbal supplements containing black elder fruits comparatively with the reference plant material by high-performance thin-layer chromatography (HPTLC) and a validated high-performance liquid chromatography (HPLC) techniques. Additionally, the total anthocyanin amount was calculated by spectrophotometry in these samples, and the results were expressed as equivalents of cyanidin-3-Oglucoside $(\mathrm{C} 3 \mathrm{G})$. HPTLC fingerprints showed that most of the marketed products did not contain rutin, chlorogenic acid and isoquercitrin. Moreover, their fingerprint comparison with the reference was found to be different. The highest chlorogenic acid, rutin and isoquercitrin amounts were found as $0.742 \mathrm{mg} /$ effervescent tablet (E3), $1.445 \mathrm{mg} /$ capsule (C1), and $0.082 \mathrm{mg} /$ capsule (C1), respectively by HPLC. According to the total anthocyanin content, $\mathrm{C} 1$ was determined to have the highest anthocyanin content as $8.705 \mathrm{mg} \mathrm{C} 3 \mathrm{G} /$ capsule, whereas E6 was found to have the lowest anthocyanin content as $0.024 \mathrm{mg}$ C3G/effervescent tablet. Consequently, there is an urgent need to establish standardization parameters for black elder fruits.
\end{abstract}

KEYWORDS: Sambucus nigra L.; black elder; high-performance thin-layer chromatography (HPTLC); highperformance liquid chromatography (HPLC); spectrophotometry; quality control.

\section{INTRODUCTION}

Common cold and flu are the most common diseases in human beings caused by viral infection of the upper respiratory tract. The 'Flu epidemic', which is widespread due to the weather conditions that frequently change during seasonal transitions, is a routine that is repeated every year. It is reported that approximately $9 \%$ of the world's population is infected every year, resulting in up to 5 million severe cases and nearly 500.000 deaths [1]. Although the number of flu-caused deaths is frightening, the main reason for this panic is the lack of effective options either for prophylaxis or treatment against viral infections. Current available applications are vaccination and neuraminidase inhibitors (i.e. oseltamivir). However, their effectiveness remains limited as the viruses may undergo rapid structural transitions or increased drug-resistance cases [2]. Therefore, scientists have been looking for alternative solutions in fighting against viral infections.

Sambucus nigra L. belongs to the genus Sambucus (Adoxaceae) is commonly known as elder, black elder, European elder etc. Its flowers, leaves and fruits contain mainly phenolic compounds as phenolic acids (caffeic acid, ferulic acid, $p$-coumaric acid) and flavonoids (rutin, isoquercitrin, kaempferol). In the European Pharmacopoeia, flavonoid content of black elder flowers expressed as isoquercitrin should be minimum $0.8 \%$. Besides, rutin, chlorogenic acid, hyperoside and caffeic acid were also assigned as identification markers [3]. On the other hand, anthocyanins (cyanidin-3-sambubioside, cyanidin-3-glucoside, pelargonidin-3sambubioside, peonidin-3-glucoside), contributing the blue, purple, and red colours, are markedly present in the fruits [4]. A wide range of pharmacological effects, i.e., antiviral, antimicrobial, anti-inflammatory, antioxidant, and cytotoxic activities, have been reported for the fruits [5]. Recently, due to the increased

How to cite this article: Güzelmeriç E, Çelik C, Şen NB, Oçkun MA, Yeşilada E. Quali/quantitative research on herbal supplements containing black elder (Sambucus nigra L.) fruits. J Res Pharm. 2021; 25(3): 238-248. 
interest in antiviral drugs, scientists have particularly focused on elucidating its mechanism of action underlying antiviral activity among the various health benefits of black elder fruits. An in-vitro trial demonstrated that flavonoids in black elder fruits might bind to H1N1 virions and prevent the ability to infect host cells [6]. According to the results of a meta-analysis of four clinical studies, extracts from the black elder fruits may significantly reduce the upper respiratory symptoms induced by viral infections [7].

Although there is a lack of clinical evidence on the efficacy of flowers of black elder against cold and influenza, such utilisation has been approved by the authorised institutions such as World Health Organization (WHO), German Commission E and European Scientific Cooperative on Phytotherapy (ESCOP) [8-10]. Moreover, its standardisation parameters were described in the monographs in several pharmacopoeias, including European Pharmacopoeia [3]. Although black elder fruits were clinically evidencing the same utilisation as the flowers, it has not been included in any pharmacopoeias. On the other hand, an increasing number of herbal supplements containing black elder fruits from different commercially available brands are recently marketed worldwide. However, there is no officially defined quality parameters for its fruits.

This study aimed to qualitatively and quantitatively investigate the marker components (chlorogenic acid, rutin and isoquercitrin) in marketed supplements containing black elder fruits comparatively with the reference plant material (black elder fruits collected from nature) by using high-performance thin-layer chromatography (HPTLC) and high-performance liquid chromatography (HPLC). Moreover, total anthocyanin content (expressed as cyanidin 3-O-glucoside (C3G)) was calculated by a $\mathrm{pH}$ differential spectroscopic method.

\section{RESULTS}

\subsection{HPTLC analysis}

In this study, the reference plant extract (black elder fruits) and the marketed herbal supplements containing black elder fruits were comparatively evaluated with the standard mixture (STD MIX: rutin, chlorogenic acid and isoquercitrin) and C3G.

To evaluate the rutin, chlorogenic acid and isoquercitrin contents in the marketted capsule or effervescent tablet formulations, the silica gel coated HPTLC plates were developed with ethyl acetate-acetic acid-formic acid-water (100:11:11:26, $v / v / v / v)$ and derivatised with NP and PEG 400 [11]. Then, the plates were captured at $366 \mathrm{~nm}$ (Figure 1 and 2). HPTLC fingerprints of the reference plant material and the formulations (capsules) were shown in Figure 1. Figure 1A shows equal applications $(5 \mu \mathrm{L})$ of each sample test solutions on the HPTLC plate with the same concentrations $(50 \mathrm{mg} / \mathrm{mL})$. While, in Figure 1B, the sample test solutions were applied in different concentrations on HPTLC plate, which were proportional to the extract amount in each capsule ( $100 \mu \mathrm{g} /$ per band). Consequently, HPTLC fingerprints of the reference fruit material and C1 were found to be similar in terms of investigated compounds (rutin, chlorogenic acid and isoquercitrin). Besides $\mathrm{C} 1$, rutin was also found in $\mathrm{C} 3$ as a fading zone. Chlorogenic acid was markedly detected in C1, C3 and $\mathrm{C} 4$. On the other hand, isoquercitrin was only found in C1.

In Figure 2, HPTLC fingerprints of the reference plant material and effervescent tablets were illustrated. Figure 2A shows the HPTLC chromatogram of sample test solutions $(200 \mathrm{mg} / \mathrm{mL})$ were applied in equal volumes $(5 \mu \mathrm{L})$. Figure $2 \mathrm{~B}$ shows the sample test solutions were applied in different concentrations on HPTLC plate, which were proportional to the extract amount in each effervescent formulation $(\sim 100 \mu \mathrm{g} / \mathrm{per}$ band). However, when the sample test solutions were applied in different concentrations to obtain an average 100 $\mu \mathrm{g} / \mathrm{band}$, the other ingredients in the formulations produced a migration problem. The marker components were not detected on the chromatogram for E6 and E7; they were not further evaluated for the qualification tests. Rutin and isoquercitrin were only found in E5. Chlorogenic acid was notably observed in most effervescent formulations (E1, E3, E4, and E5).

$n$-Butanol-water-formic acid $(65: 19: 16, v / v / v)$ was used as a developing solvent system to evaluate the anthocyanin contents in samples together with C3G [12]. After development, HPTLC plates were assessed under white light (Figure 3 and 4). In Figure 3, HPTLC fingerprints of the reference fruit material and capsule formulations were shown. The same methodology, as clearly described above, was applied, and Figure 3A presents the results of the sample test solutions with the same concentrations and application amounts. On the other hand, Figure 3B shows sample test solutions in $\sim 100 \mu \mathrm{g} /$ per band. Bands with reddish colour indicated anthocyanins in the sample test solutions. As a result, main anthocyanin components were detected in the reference fruit material at $R_{\mathrm{F}} \approx 0.3, R_{\mathrm{F}} \approx 0.4, R_{\mathrm{F}} \approx 0.55$ and $R_{\mathrm{F}} \approx 0.7(\mathrm{C} 3 \mathrm{G})$. 


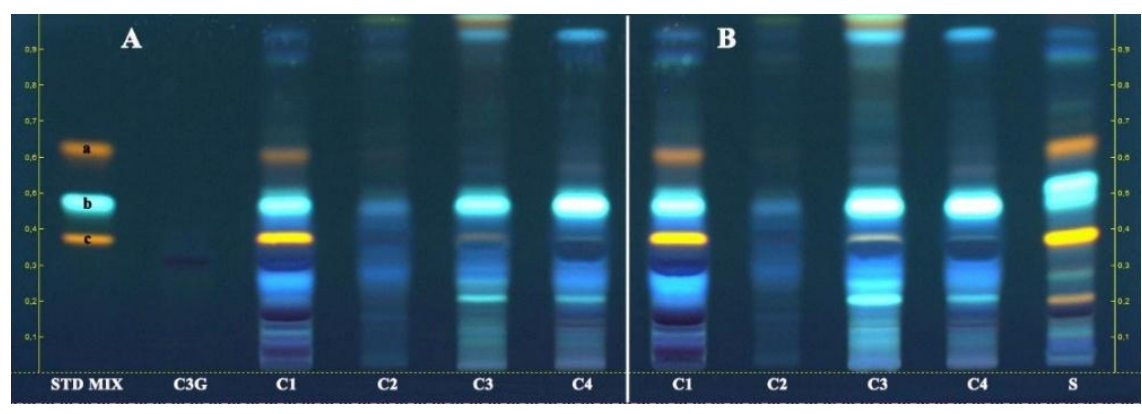

Figure 1. HPTLC chromatogram of hydroalcoholic extract of black elder fruits (reference, encoded as S) and its capsule formulations captured at $366 \mathrm{~nm}$ after derivatisation with NP and PEG reagents, sequentially. A: Sample test solutions were applied as $5 \mu \mathrm{L}$, B: Sample test solutions were applied in different volumes to provide $100 \mu \mathrm{g}$ black elder fruit extract per band. STD MIX: a: isoquercitrin, b: chlorogenic acid, c: rutin.

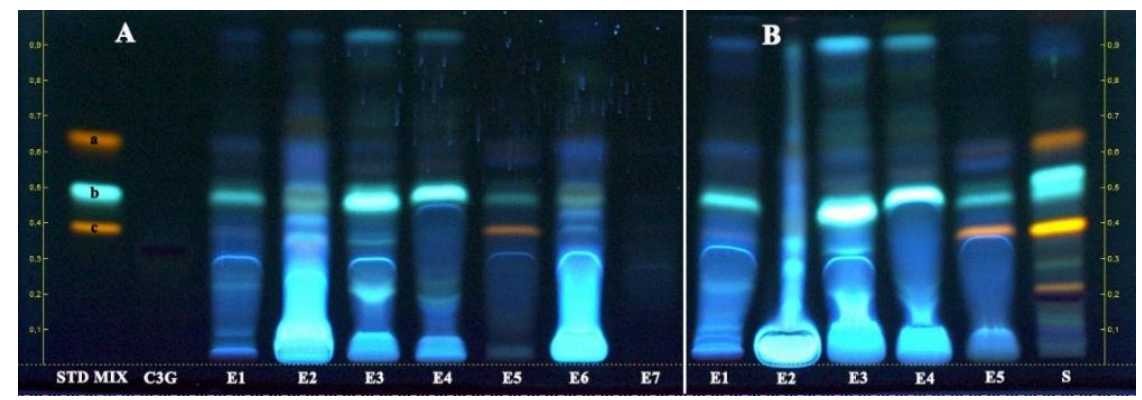

Figure 2. HPTLC chromatogram of hydroalcoholic extract of black elder fruits (reference, encoded as S) and its effervescent formulations captured at $366 \mathrm{~nm}$ after derivatisation with NP and PEG reagents, sequentially. A: Sample test solutions were applied as $5 \mu \mathrm{L}$, B: Sample test solutions were applied in different volumes to obtain $100 \mu \mathrm{g}$ black elder fruit extract per band. STD MIX: a: isoquercitrin, b: chlorogenic acid, c: rutin.

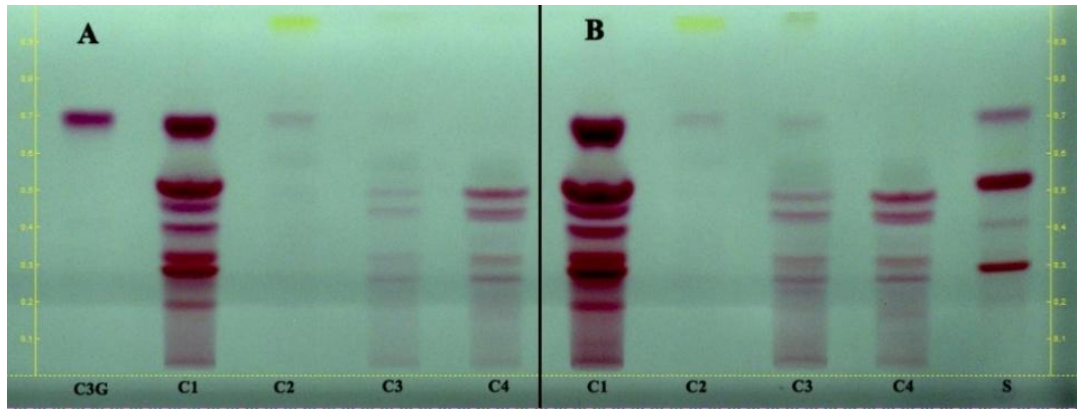

Figure 3. HPTLC chromatogram of hydroalcoholic extract of black elder fruits (reference, encoded as S) and its capsule formulations captured under white light. A: Sample test solutions were applied as $5 \mu \mathrm{L}$, B: Sample test solutions were applied in different volumes to obtain $100 \mu \mathrm{g}$ black elder fruit extract per band.

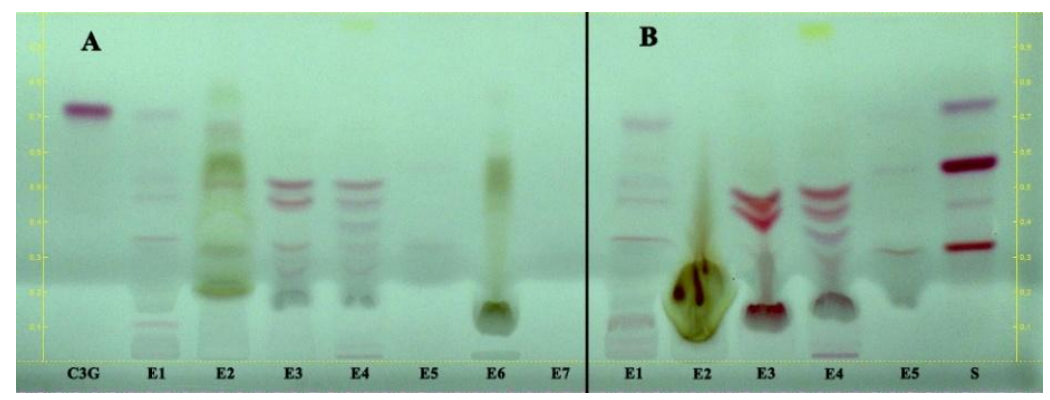

Figure 4. HPTLC chromatogram of hydroalcoholic extract of black elder fruits (reference, encoded as S) and its effervescent formulations captured under white light. A: Sample test solutions were applied as $5 \mu \mathrm{L}, \mathrm{B}$ : Sample test solutions were applied in different volumes to obtain $100 \mu \mathrm{g}$ black elder fruit extract per band. 
Similarly, these main components were also observed in C1. HPTLC fingerprint of C1 has clearly shown that it contains various anthocyanin-type constituents. On the other hand, $\mathrm{C} 2$ was found to have the least anthocyanin content. In a perspective of C3G content, it was detected in all samples in varying amounts except C4.

HPTLC fingerprints of the reference fruit material and the effervescent formulations were presented in Figure 4. Figure 4A illustrates the sample test solutions were applied in the same concentration and the same application amounts as described above. On the other hand, Figure 4B shows the sample test solutions were applied in $\sim 100 \mu \mathrm{g} /$ per band concentration. Consequently, C3G was only detected in E1 as a faded zone. Anthocyanins were observed in all samples except E6 and E7, possibly due to the lower extract amount in these effervescent formulations than the others.

\subsection{HPLC analysis}

\subsubsection{HPLC method validation}

For quantification of chlorogenic acid, rutin and isoquercitrin, an HPLC method was newly developed and validated according with International Conference on Harmonisation (ICH) guidelines for specificity, linearity $\left(r^{2}\right)$, detection and determination limits (LOD and LOQ, respectively), precision (intra/interdays) and accuracy [13].

To evaluate the specificity of the method, the chromatograms of the least concentration of the working standard solutions were comparatively analysed with the blank chromatogram. Consequently, investigated compounds chlorogenic acid (retention time $\left.\left(t_{R}\right)=4.543 \pm 0.004\right)$, rutin $\left(t_{R}=8.496 \pm 0.007\right.$ ) and isoquercitrin $\left(t_{R}=9.530 \pm 0.004\right)$ were not monitored on the blank chromatogram indicating the specificity of the developed method. Additionally, to detect the investigated compounds in the samples, UV spectrums of chlorogenic acid, rutin and isoquercitrin were compared with the compounds found in the sample test solution.

To determine the linearity, seven different concentration levels of each standard compound were analysed thrice. The calibration curve for chlorogenic acid, rutin and isoquercitrin were within the ranges of $0.25-20 \mu \mathrm{g} / \mathrm{mL}, 1.25-100 \mu \mathrm{g} / \mathrm{mL}$ and $0.25-20 \mu \mathrm{g} / \mathrm{mL}$, respectively, and were found to be linear with $r^{2}=0.9994$ to 0.9999 (Table 1).

LOD and LOQ values which were calculated by using the following equation as $3.3 \times(\mathrm{SD} / \mathrm{S})$ and $10 \mathrm{x}$ (SD/S) for chlorogenic acid, rutin and isoquercitrin were found as $0.10 \mu \mathrm{g} / \mathrm{mL}$ and $0.34 \mu \mathrm{g} / \mathrm{mL}, 0.49 \mu \mathrm{g} / \mathrm{mL}$ and $1.62 \mu \mathrm{g} / \mathrm{mL}, 0.12 \mu \mathrm{g} / \mathrm{mL}$ and $0.39 \mu \mathrm{g} / \mathrm{mL}$, respectively.

Table 1. Linearity data for chlorogenic acid, rutin and isoquercitrin calibration curves.

\begin{tabular}{lccccccc}
\hline \multicolumn{1}{c}{ Standards } & $\begin{array}{c}\text { Linearity } \\
\text { range }\end{array}$ & $\mathbf{r}^{2}$ & $\mathbf{S}$ & Intercept & $\mathbf{S D}$ & $\begin{array}{c}\text { LOD } \\
\boldsymbol{\mu g} / \mathbf{m L}\end{array}$ & $\begin{array}{c}\mathbf{L O Q} \\
\boldsymbol{\mu g} / \mathbf{m L}\end{array}$ \\
\hline Chlorogenic acid & $0.25-20$ & 0.9998 & 23.93 & 0.1102 & 0.81 & 0.10 & 0.34 \\
Rutin & $1.25-100$ & 0.9999 & 17.097 & 3.3712 & 2.77 & 0.49 & 1.62 \\
Isoquercitrin & $0.25-20$ & 0.9994 & 28.367 & 3.4667 & 1.10 & 0.12 & 0.39 \\
\hline
\end{tabular}

The intraday precision was evaluated by repeating the analysis thrice during the day, whereas interday precision was assessed by repeating the analysis thrice on consecutive days. The results found were shown in Table 2. To evaluate accuracy of the developed method, three different concentrations of the investigated standards were analysed thrice, and the obtained results were compared with the theoretical values, shown in Table 3.

\subsubsection{Chlorogenic acid, rutin and isoquercitrin contents in black elder fruits and marketed supplements}

Using a validated HPLC method, chlorogenic acid, rutin and isoquercitrin contents were quantified in black elder fruit material which was used as reference and its marketed food supplements (Figure 5). Accordingly, the contents of chlorogenic acid, rutin and isoquercitrin were calculated as $0.726 \pm 0.002 \mathrm{mg} / \mathrm{g}$, $10.178 \pm 0.017 \mathrm{mg} / \mathrm{g}$ and $1.165 \pm 0.002 \mathrm{mg} / \mathrm{g}$, respectively, in the reference fruit extract. 


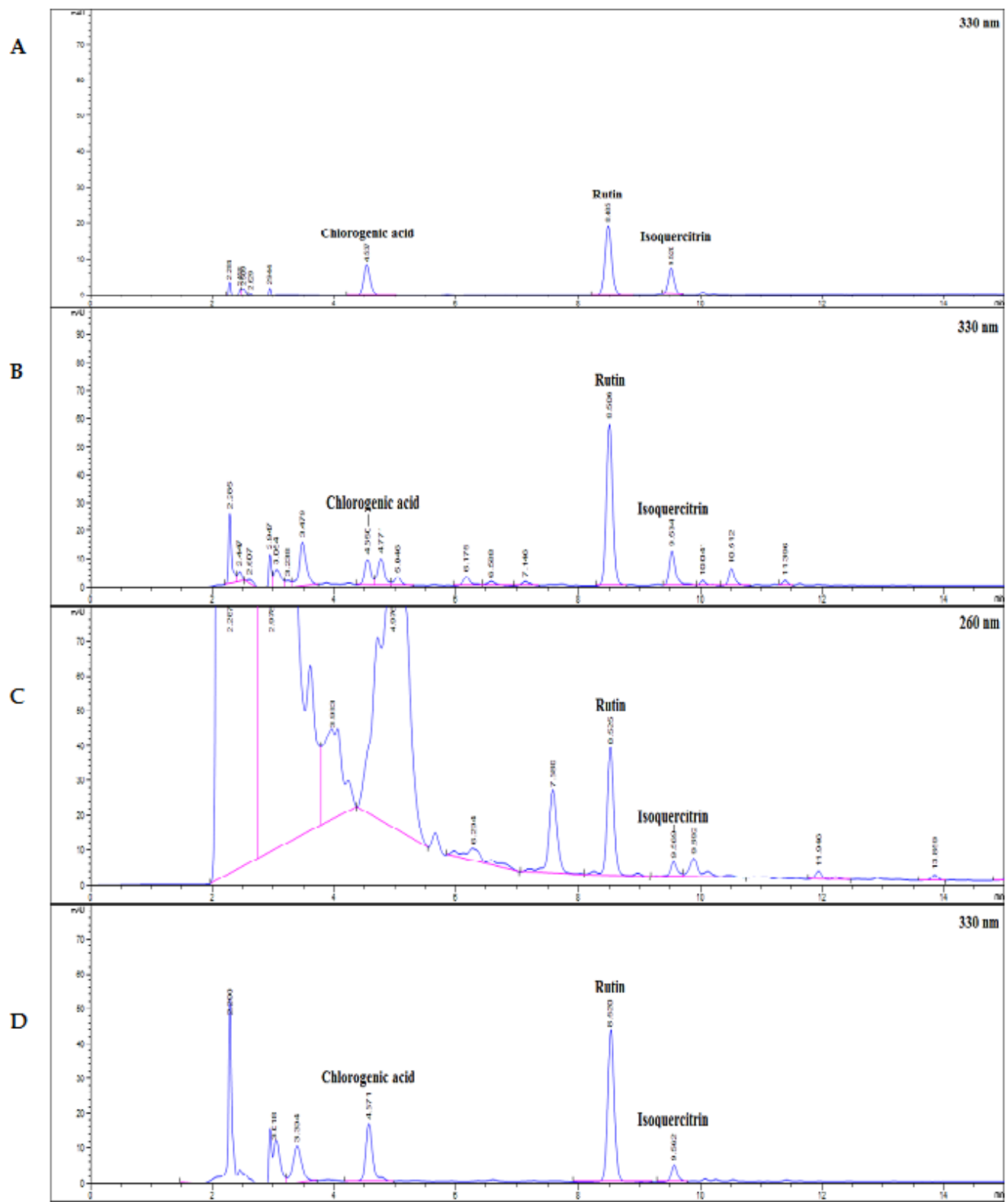

Figure 5. HPLC chromatograms of the standard mixture solution at $330 \mathrm{~nm}(\mathrm{~A})$, the solutions of reference plant material at $330 \mathrm{~nm}(\mathrm{~B}), \mathrm{E} 2$ at $260 \mathrm{~nm}(\mathrm{C})$ and $\mathrm{C} 1$ at $330 \mathrm{~nm}(\mathrm{D})$.

Table 2. Repeatability and interprecision data for chlorogenic acid, rutin and isoquercitrin.

\begin{tabular}{|c|c|c|c|c|c|c|c|}
\hline \multirow[b]{2}{*}{ Standards } & \multirow[b]{2}{*}{ Concentration } & \multicolumn{2}{|c|}{ Intraday precision } & \multicolumn{2}{|c|}{ Interday precision } & \multicolumn{2}{|c|}{ Interday precision } \\
\hline & & $\begin{array}{c}\text { Average } \\
(\mu \mathrm{g} / \mathbf{m L} \pm \mathrm{SD}) \\
n=3\end{array}$ & RSD & $\begin{array}{c}\text { Average } \\
(\mu \mathrm{g} / \mathrm{mL} \pm \mathrm{SD}) \\
n=3\end{array}$ & RSD & $\begin{array}{c}\text { Average } \\
(\mu \mathrm{g} / \mathrm{mL} \pm \mathrm{SD}) \\
n=3\end{array}$ & RSD \\
\hline $\begin{array}{l}\text { Chlorogenic } \\
\text { acid }\end{array}$ & $2.5 \mu \mathrm{g} / \mathrm{mL}$ & $\begin{array}{l}2.562 \pm 0.008 \\
2.577 \pm 0.009 \\
2.573 \pm 0.002\end{array}$ & $\begin{array}{l}0.326 \\
0.338 \\
0.094\end{array}$ & $2.563 \pm 0.011$ & 0.410 & $\begin{array}{c}2.580 \pm \\
0.002\end{array}$ & 0.094 \\
\hline Rutin & $12.5 \mu \mathrm{g} / \mathrm{mL}$ & $\begin{array}{l}12.893 \pm 0.020 \\
12.936 \pm 0.021 \\
12.930 \pm 0.015\end{array}$ & $\begin{array}{l}0.157 \\
0.159 \\
0.114\end{array}$ & $\begin{array}{c}12.935 \pm \\
0.012\end{array}$ & 0.094 & $\begin{array}{c}12.969 \pm \\
0.010\end{array}$ & 0.078 \\
\hline Isoquercitrin & $2.5 \mu \mathrm{g} / \mathrm{mL}$ & $\begin{array}{l}2.654 \pm 0.077 \\
2.664 \pm 0.009 \\
2.669 \pm 0.006\end{array}$ & $\begin{array}{l}0.077 \\
0.333 \\
0.230\end{array}$ & $2.666 \pm 0.006$ & 0.229 & $\begin{array}{c}2.666 \pm \\
0.006\end{array}$ & 0.229 \\
\hline
\end{tabular}


Table 3. Recovery study results for chlorogenic acid, rutin and isoquercitrin.

\begin{tabular}{ccccc}
\hline Standards & $\begin{array}{c}\text { Theoretical value } \\
(\boldsymbol{\mu g} / \mathbf{m L}) \mathbf{n}=\mathbf{3}\end{array}$ & $\begin{array}{c}\text { Amount found } \\
(\boldsymbol{\mu} \mathrm{g} / \mathbf{m L} \pm \mathbf{S D}) \mathbf{n}=\mathbf{3}\end{array}$ & $\begin{array}{c}\text { Recovery } \\
(\mathbf{\%})\end{array}$ & RSD \\
\hline Chlorogenic & 3.75 & $3.744 \pm 0.000$ & 100.638 & 0.000 \\
acid & 7.5 & $7.386 \pm 0.017$ & 98.478 & 0.236 \\
& 15 & $14.743 \pm 0.036$ & 98.290 & 0.242 \\
\cline { 2 - 5 } Rutin & 20 & $20.988 \pm 0.025$ & 104.939 & 0.121 \\
& 40 & $40.184 \pm 0.108$ & 100.460 & 0.270 \\
\cline { 2 - 5 } Isoquercitrin & 80 & $80.197 \pm 0.027$ & 100.246 & 0.033 \\
& 3.75 & $3.844 \pm 0.080$ & 102.498 & 2.073 \\
& 7.5 & $7.610 \pm 0.025$ & 101.464 & 0.329 \\
\hline
\end{tabular}

E3 was found to have the highest chlorogenic acid content as $0.742 \mathrm{mg} /$ effervescent tablet. Additionally, the highest rutin and isoquercitrin contents were calculated in C1 as $1.445 \mathrm{mg} /$ capsule and $0.082 \mathrm{mg} / \mathrm{capsule}$, respectively. The obtained results were shown in Table 4.

Table 4. Quantitative results of chlorogenic acid, rutin and isoquercitrin in the marketed samples by HPLC.

\begin{tabular}{|c|c|c|c|c|}
\hline Samples & & $\begin{array}{l}\text { Chlorogenic acid } \\
(\mathrm{mg} \pm \mathrm{SD})\end{array}$ & Rutin $(m g \pm S D)$ & Isoquercitrin $(\mathrm{mg} \pm \mathrm{SD})$ \\
\hline $\mathrm{C} 1$ & 0 & $0.271 \pm 0.000$ & $1.445 \pm 0.002$ & $0.082 \pm 0.001$ \\
\hline $\mathrm{C} 2$ & F & n.d. & n.d. & n.d. \\
\hline $\mathrm{C} 3$ & च्త & $0.497 \pm 0.001$ & $0.086 \pm 0.001$ & n.d. \\
\hline $\mathrm{C} 4$ & $r$ & $0.681 \pm 0.002$ & n.d. & n.d. \\
\hline E1 & 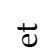 & $0.117 \pm 0.000$ & n.d. & $0.004 \pm 0.000$ \\
\hline E2 & $\frac{\pi}{\pi}$ & n.d. & $0.275 \pm 0.002$ & $0.019 \pm 0.002$ \\
\hline E3 & \pm & $0.742 \pm 0.003$ & n.d. & n.d. \\
\hline E4 & 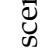 & $0.539 \pm 0.006$ & n.d. & n.d. \\
\hline E5 & $\sum^{0}$ & $0.055 \pm 0.000$ & $0.216 \pm 0.000$ & $0.013 \pm 0.000$ \\
\hline E6 & 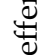 & n.d. & n.d. & n.d. \\
\hline E7 & $\rightarrow$ & n.d. & n.d. & n.d. \\
\hline
\end{tabular}

\subsection{Total anthocyanin content}

A spectroscopic method was used to determine the total anthocyanin content. In the reference fruit material, total anthocyanin content was $7.5 \mathrm{mg} / \mathrm{g} \mathrm{C3G}$ equivalent. The results of the marketed samples were shown in Table 5. Among the capsule formulations, C1 was determined to possess the highest anthocyanin content as $8.705 \mathrm{mg} \mathrm{C} 3 \mathrm{G} /$ capsule, while C2 was found to have the least anthocyanin content as $0.259 \mathrm{mg}$ C3G/capsule. Unexpectedly, according to the labelled information, C2 was claimed to have the highest black elder fruit extract content, as $270 \mathrm{mg}$ per capsule (Table 5).

The content of black elder fruit extract was within the ranges of 5-200 $\mathrm{mg}$ in the effervescent formulations according to the given information on the package. However, the highest anthocyanin content was determined in E1 formulation, and it was only $0.366 \mathrm{mg} \mathrm{C} 3 \mathrm{G} /$ effervescent tablet. Besides, E7 contained the lowest extract content $(5 \mathrm{mg}$ ), and only $0.027 \mathrm{mg}$ the anthocyanin content per effervescent tablet was determined. On the other hand, E6 labeled to contain $160 \mathrm{mg}$ extract, the anthocyanin content was found lower than E7 (Table 5).

\section{DISCUSSION}

In this study, commercially available herbal supplements containing black elder fruits were qualitatively and quantitatively evaluated to obtain an insight into their product quality. Since not any standard procedure was described for the quality assessment of fruits, the comparison was directly made by the fruit extract obtained from the plant (reference). 
Table 5. Total anthocyanin content in the marketed samples.

\begin{tabular}{|c|c|c|c|c|c|}
\hline \multicolumn{2}{|c|}{ Samples } & \multirow{2}{*}{$\begin{array}{c}\begin{array}{c}\text { Total } \\
\text { weight of } \\
\text { samples } \\
\text { (mg) }\end{array} \\
495\end{array}$} & \multirow{2}{*}{$\begin{array}{c}\begin{array}{c}\text { Extract of black } \\
\text { elder fruits weight } \\
\text { in samples (mg) }\end{array} \\
127\end{array}$} & \multirow{2}{*}{$\begin{array}{c}\text { Percentage of black } \\
\text { elder fruit extract in } \\
\text { samples (\%) }\end{array}$} & \multirow{2}{*}{$\begin{array}{c}\begin{array}{c}\text { Total anthocyanin } \\
\text { content in samples } \\
(\mathbf{m g})\end{array} \\
8.705 \pm 0.12^{\mathrm{a}}\end{array}$} \\
\hline $\mathrm{C} 1$ & 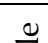 & & & & \\
\hline $\mathrm{C} 2$ & ह & 567 & 270 & 47.619 & $0.259 \pm 0.004 \mathrm{fg}$ \\
\hline $\mathrm{C} 3$ & चै & 815 & 120 & 14.724 & $1.127 \pm 0.095 \mathrm{~b}$ \\
\hline $\mathrm{C} 4$ & 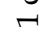 & 446 & 150 & 33.632 & $0.856 \pm 0.099 c$ \\
\hline E1 & 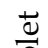 & 3500 & 200 & 5.714 & $0.366 \pm 0.036$ ef \\
\hline E2 & 疋 & 3500 & 150 & 4.286 & $0.538 \pm 0.024 \mathrm{de}$ \\
\hline E3 & $\vec{t}$ & 4000 & 150 & 3.750 & $1.1 \pm 0.065 \mathrm{~b}$ \\
\hline E4 & $\stackrel{\mathscr{U}}{0}$ & 3500 & 160 & 4.571 & $0.682 \pm 0.057 \mathrm{~cd}$ \\
\hline E5 & 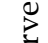 & 4100 & 151.7 & 3.700 & $0.155 \pm 0.03 \mathrm{gh}$ \\
\hline E6 & 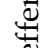 & 3500 & 160 & 4.571 & $0.024 \pm 0.012 \mathrm{~h}$ \\
\hline E7 & $\stackrel{1}{1}$ & 4500 & 5 & 0.111 & $0.027 \pm 0.002 \mathrm{~h}$ \\
\hline
\end{tabular}

According to the European Pharmacopoeia, black elder flowers are standardized by their isoquercitrin contents. Besides, rutin, chlorogenic acid, hyperoside and caffeic acid are also determined as marker components for identification [3]. Therefore, in this study, one of the marker components was assigned as isoquercitrin. Other marker components such as rutin and chlorogenic acid were selected according to the HPTLC profile since these components were identified as the main compounds on the HPTLC chromatogram, whereas hyperoside and caffeic acid were not detected in the reference fruit extract. Consequently, qualitative and quantitative analysis of rutin, chlorogenic acid and isoquercitrin were evaluated comparatively in the test samples by HPTLC and HPLC techniques. These compounds were also reported as the main active ingredients of the plant responsible for the pharmacologic effects such as antioxidant, antitumor, immunostimulating activities [14]. All the investigated compounds (rutin, chlorogenic acid and isoquercitrin) were monitored in the reference fruit extract by HPTLC. Among the marketed 11 different herbal supplements (4 capsule formulations and 7 effervescent formulations), marker components were detected in C1 and E5 samples by HPTLC fingerprinting. Surprisingly, most of the products analysed did not contain any rutin and isoquercitrin. The amounts of chlorogenic acid, rutin and isoquercitrin were assessed as $0.726 \pm 0.002 \mathrm{mg} / \mathrm{g}$, $10.178 \pm 0.017 \mathrm{mg} / \mathrm{g}$ and $1.165 \pm 0.002 \mathrm{mg} / \mathrm{g}$ in the reference fruit extract by HPLC, respectively. In the previous reports on black elder fruits, the concentrations of these components were found within the ranges for chlorogenic acid 0.1-46 mg/g, for rutin 0.5-54 mg/g and for isoquercitrin 0.06-18 mg/g [15-18]. In another study, unprocessed black elder fruits obtained from different herbal manufacturers in Poland were analysed by HPLC. Accordingly, rutin content was found in the ranges of $18.9-335.8 \mu \mathrm{g} / \mathrm{g}$ and chlorogenic acid content was found in between 6.8-43.7 $\mu \mathrm{g} / \mathrm{g}$ [19]. Taken together, found results for the reference fruit material were found to be consistent with these previously reported data. According to the results obtained in this study, the highest chlorogenic acid, rutin and isoquercitrin amounts were determined as $0.742 \mathrm{mg} /$ effervescent tablet (E3), $1.445 \mathrm{mg} /$ capsule (C1) and $0.082 \mathrm{mg} /$ capsule $(\mathrm{C} 1)$ in the commercial formulations, respectively. However, these marker components were not detected in C2, E6 and E7.

Black elder fruit comparing to other fruits, has been reported to contain higher rates of anthocyanins [20]. The total anthocyanin content in black elder fruit may vary between $2.42-18.16 \mathrm{mg} / \mathrm{g}$ in fresh weight and $4.08-101.4 \mathrm{mg} / \mathrm{g}$ in dry weight according to the climate and collection cite [21-29]. In this study, total anthocyanin content was found as $7.5 \mathrm{mg} / \mathrm{g}$ in the reference fruit material.

In clinical studies, the daily suggested doses of anthocyanins were described as approximately $100 \mathrm{mg}$ for the treatment of metabolic syndrome disorders and $3.5 \mathrm{~g}$ for influenza [30]. In a previous study, standardised liquid black elder fruit extract (containing \%3.2 anthocyanin) was reported to possess antimicrobial activity against human respiratory bacterial pathogens and influenza A and B viruses [31]. A randomised clinical investigation reported that consumption of 600-900 $\mathrm{mg}$ per day (containing 90-135 mg anthocyanin) black elder fruit extract may significantly reduce the severity and duration of cold-related respiratory symptoms [32]. Despite these previous studies, total anthocyanin contents in the commercial herbal supplements investigated in the present study has remained far below these ranges, i.e. 0.024-8.705 mg C3G/per sample. 


\section{CONCLUSION}

The application of quality control parameters to the raw herbal materials and the finished products before marketing is a supreme parameter for reproducible pharmacological activity. Due to a wide range of health benefits proven scientifically, an increasing demand for herbal supplements containing black elder fruits are observed on the market. However, no official procedure has been described for its qualification. For this reason, a monograph that determines its chemical content and quality criteria is needed.

\section{MATERIALS AND METHODS}

\subsection{Chemicals and solvents}

HPLC grade acetonitrile and the other solvents were analytical grade and purchased from SigmaAldrich (Steinheim, Germany). Standard compounds of chlorogenic acid, rutin, isoquercitrin were acquired from Sigma-Aldrich (Steinheim, Germany), and cyanin-3-O-glucoside was from Phyproof (Vestenbergsgreuth, Germany).

\subsection{Black elder fruits material and its marketed herbal supplements}

Black elder fruits were collected in Bayramiç (Çanakkale, Turkey) and used as reference fruit material (a voucher specimen (YEF 20007) has been kept at the Herbarium of the Department of Pharmacognosy, Faculty of Pharmacy, Yeditepe University, Istanbul, Turkey) during the study. The capsule (C1-4) and effervescent (E1-7) formulations were supplied from the pharmacies. The amount of extract of black elder fruits declared on the packages of these commercial formulations ranged from $5 \mathrm{mg}$ to $270 \mathrm{mg}$.

\subsection{Preparation of standard solutions}

\subsubsection{Standard solutions for HPTLC analysis}

Standard solutions of rutin, chlorogenic acid, isoquercitrin and cyanidin-3-O-glucoside were prepared in methanol at $0.2 \mathrm{mg} / \mathrm{mL}$ concentration. To prepare STD MIX, equal volumes of rutin, chlorogenic acid and isoquercitrin standard solutions were mixed.

\subsubsection{Standard solutions for HPLC analysis}

Stock solutions of rutin $(300 \mu \mathrm{g} / \mathrm{mL})$, chlorogenic acid $(300 \mu \mathrm{g} / \mathrm{mL})$ and isoquercitrin $(60 \mu \mathrm{g} / \mathrm{mL})$ were prepared in methanol and also diluted for calibration curve and recovery studies.

\subsubsection{Standard solutions for spectrophotometry}

A stock solution of cyanidin-3-O-glucoside was prepared in methanol at $0.2 \mathrm{mg} / \mathrm{mL}$ concentration and diluted to obtain a calibration curve.

\subsection{Preparation of sample test solutions}

\subsubsection{Extraction of black elder fruits as a reference material}

Weighed $1 \mathrm{~g}$ of powdered black elder fruits collected from Bayramiç (Çanakkale) in Turkey, was extracted with $20 \mathrm{~mL}$ methanol-water $(7: 3, v / v)$. The hydroalcoholic extract was sonicated for 30 minutes. After filtration, the liquid part was evaporated under vacuum to obtain the extract. The extract was diluted with methanol and filtered by a $0.45 \mu \mathrm{m}$ syringe filter for further analysis.

\subsubsection{Extraction of marketed black elder fruits supplements}

For each effervescent formulation, 1 effervescent tablet was dissolved with $100 \mathrm{~mL}$ of distilled water and lyophilised. Then, $5 \mathrm{~mL}$ of methanol was added to $1 \mathrm{~g}$ of lyophilised sample. After sonication, the solution was filtered by a $0.45 \mu \mathrm{m}$ syringe filter. For each capsule formulation, $10 \mathrm{~mL}$ of methanol was added to 0.5 $\mathrm{mg}$ of sample, which was weighed from a homogeneous mixture of 3 capsules. After sonication, the solution was filtered by a $0.45 \mu \mathrm{m}$ syringe filter.

\subsection{HPTLC method}

Sample test solutions of marketed supplements (capsules and effervescent tablets), reference plant material, mixture of standard solutions (STD MIX $(5 \mu \mathrm{L})$ and C3G $(2 \mu \mathrm{L}))$ were applied as bands using a 
Linomat V semi-automatic sample applicator (Camag, Muttenz, Switzerland) coupled with $100 \mu \mathrm{L}$ Hamilton syringe on HPTLC plate (silica gel $60 \mathrm{~F} 254$ glass plate, $20 \times 10 \mathrm{~cm}$ ). Two different solvents were used as mobile phase: for phenolic acids and flavonoids; ethyl acetate-acetic acid-formic acid-water (100:11:11:26, $v / v / v / v)$ [11] and for anthocyanins; $n$-butanol-water-formic acid $(16: 19: 65, v / v / v)$ [12]. The plates were then developed up to $7 \mathrm{~cm}$ in a 20 minutes saturated twin-trough chamber (Camag). After development, the plates were heated at $100^{\circ} \mathrm{C}$ on the Camag TLC plate heater for 3 minutes and derivatised with Natural Product reagent (NP reagent) and PEG 400 solutions, respectively. Finally, the plates were documented at $366 \mathrm{~nm}$ and white light by Camag TLC visualiser.

\subsection{HPLC method}

HPLC analysis was performed by using Agilent 1260 Infinity HPLC system (Darmstadt, Germany) consisting of an Agilent ChemStation software, quaternary pump (G1311B), auto-sampler (G1329B), thermostatted column compartment (G1316A), and diode array detector (G4212B).

The Agilent Zorbax Extend RP18 Column (4.6 $\mathrm{mm} \times 250 \mathrm{~mm}, 5-\mu \mathrm{m}$ particle size) was used at $25^{\circ} \mathrm{C}$ for the separation of the investigated compounds. The gradient elution was used by using mobile phases A ( $o$ phosphoric acid-water (0.1:99.9, v/v) and B (acetonitrile). The following gradient system was applied: $15-20 \%$ B (0-5 min.), 20-34\% B (5-12 min.), 34-50\% B (12-15 min.), 50-100\% B (15-18 min.), 100\% B (18-20 min.) and 100$15 \%$ (20-23 min.). $10 \mu \mathrm{L}$ of the standard and test solutions were injected into the system. The flow rate was 1 $\mathrm{mL} / \mathrm{min}$. Chlorogenic acid was monitored at $330 \mathrm{~nm}$, whereas rutin and isoquercitrin were detected at 260 $\mathrm{nm}$. This newly developed method was validated according to the International Conference on Harmonisation (ICH) 1995 guidelines [13].

\subsection{Total anthocyanin content}

Initially, buffer solutions at $\mathrm{pH} 1$ containing $0.025 \mathrm{M}$ potassium chloride and $\mathrm{pH} 4.5$ containing $0.4 \mathrm{M}$ sodium acetate were prepared. The experiment was performed directly in a 96-well microplate by adding 40 $\mu \mathrm{L}$ test solutions and $160 \mu \mathrm{L}$ of buffer solutions at $\mathrm{pH} 1$ and $\mathrm{pH} 4.5$, respectively. The absorbance was measured at two different wavelengths, $520 \mathrm{~nm}$ and $700 \mathrm{~nm}$ [33]. The following equation 1 (Eq. 1) was performed to calculate total anthocyanin content in the sample:

$$
A=\left(A_{520 \mathrm{~nm}}-A_{700 \mathrm{~nm}}\right) p H_{1.0}-\left(A_{520 \mathrm{~nm}}-A_{700 \mathrm{~nm}}\right) p H_{4.5} \quad \text { Eq. } 1
$$

The result of reference plant material was expressed in a ratio $\mathrm{mg}$ C3G equivalents per weight of sample extract (mg C3G/g extract). For marketed samples, results were given for each capsule (mg C3G/capsule) or effervescent tablet (mg C3G/effervescent tablet).

Acknowledgements: Etil Güzelmeriç thanks the pharmacists for supplying herbal supplements used in the study.

Author contributions: Concept - E.G.; Design - E.G.; Supervision - E.G.; Resources - E.G., C.Ç., N.B.Ş., E.Y.; Materials - E.G., C.Ç., N.B.Ş., E.Y.; Data Collection and/or Processing - E.G., C.Ç., N.B.Ş.; Analysis and/or Interpretation - E.G., C.Ç., N.B.Ş., M.A.O.; Literature Search - E.G., C.Ç., N.B.Ş..M.A.O.; Writing - E.G., C.Ç., N.B.Ş., M.A.O., E.Y.; Critical Reviews - E.G., C.Ç., N.B.Ş., M.A.O., E.Y.

Conflict of interest statement: The authors declare no conflict of interest.

\section{REFERENCES}

[1] Clayville LR. Influenza update: a review of currently available vaccines. P\&T. 2011; 36(10): 659-684.

[2] Kamali A, Holodniy M. Influenza treatment and prophylaxis with neuraminidase inhibitors: a review. Infect Drug Resist. 2013; 6: 187-198. [CrossRef]

[3] European Pharmacopoeia (Ph. Eur.), Seventh ed., Council of Europe, Strasbourg, France, 2010.

[4] Porter RS, Bode RF. A review of the antiviral properties of black elder (Sambucus nigra L.) products. Phytother Res. 2017; 31(4): 533-554. [CrossRef] 
[5] Młynarczyk K, Walkowiak-Tomczak D, Łysiak GP. Bioactive properties of Sambucus nigra L. as a functional ingredient for food and pharmaceutical industry. J Funct Foods. 2018; 40: 377-390. [CrossRef]

[6] Roschek Jr B, Fink RC, McMichael MD, Li D, Alberte RS. Elderberry flavonoids bind to and prevent H1N1 infection in vitro. Phytochemistry. 2009; 70(10): 1255-1261. [CrossRef]

[7] Hawkins J, Baker C, Cherry L, Dunne E. Black elderberry (Sambucus nigra) supplementation effectively treats upper respiratory symptoms: A meta-analysis of randomised, controlled clinical trials. Complement Ther Med. 2019; 42: 361-365 [CrossRef]

[8] World Health Organization (WHO) Monographs on Selected Medicinal Plants, Geneva, 1999.

[9] The Complete German Commission E Monographs, American Botanical Council, Texas, 1998.

[10] European Scientific Cooperative on Phytotherapy (ESCOP) Monographs, Second ed., Thieme, New York, 2003.

[11] Maleš Ž, Plazibat M, Bilušić Vundać V, Žuntar I. Qualitative and quantitative analysis of flavonoids of the strawberry tree-Arbutus unedo L. (Ericaceae). Acta Pharm. 2006; 56(2): 245-250.

[12] Łata E, Fulczyk A, Kowalska T, Sajewicz M. Thin-layer chromatographic method of screening the anthocyanes containing alimentary products and precautions taken at the method development step. J Chromatogr A. 2017; 1530, 211-218. [CrossRef]

[13] ICH Harmonised Tripartite Guideline Validation of Analytical Procedures: Text and Methodology Q2 (R1). https://www.ich.org/fileadmin/Public_Web_Site/ICH_Products/Guidelines/Quality/Q2_R1/Step4/Q2_R1_G uideline.pdf (accessed on 8 August 2019).

[14] Sidor A, Gramza-Michałowska A. Advanced research on the antioxidant and health benefit of elderberry (Sambucus nigra) in food-a review. J Funct Foods. 2015; 18: 941-958. [CrossRef]

[15] Vrchotová N, Dadáková E, Matějiček A, Tř́iska J, Kaplan J. Effect of variety on content of bioactive phenolic compounds in common elder (Sambucus nigra L.). Nat Prod Res. 2017; 31(6): 700-703. [CrossRef]

[16] Nagl M, Eder R, Wendelin S, Reich G, Sontag G. Qualitative and quantitative analysis of phenolic constituents in elderberry juices. Nutrition Vienna 2006; 30(10): 409-415.

[17] Mudge E, Applequist WL, Finley J, Lister P, Townesmith AK., Walker KM., Brown, PN. Variation of select flavonols and chlorogenic acid content of elderberry collected throughout the Eastern United States. J Food Compos Anal. 2016; 47: 52-59. [CrossRef]

[18] Dawidowicz AL., Wianowska D, Baraniak B. The antioxidant properties of alcoholic extracts from Sambucus nigra L. (antioxidant properties of extracts). LWT-Food Sci. Technol. 2006; 39(3): 308-315. [CrossRef]

[19] Viapiana A, Wesolowski M. HPLC fingerprint combined with quantitation of phenolic compounds and chemometrics as an efficient strategy for quality consistency evaluation of Sambucus nigra berries. Nat. Prod. Commun. 2016; 11(10): 1934578X1601101009. [CrossRef]

[20] Csorba V, Toth M, Laszlo A, Kardos L, Kovacs S. Cultivar and year effects on the chemical composition of elderberry (Sambucus nigra L.) fruits. Notulae Botanicae Horti Agrobotanici Cluj-Napoca. 2020; 48(2): 770-782. [CrossRef]

[21] Tosun M, Ercisli S, Akbulut M. Physicochemical characteristics of some wild grown European elderberry (Sambucus nigra L.) genotypes. Pharmacogn Mag. 2009; 5(20): 320-323. [CrossRef]

[22] Anton AM, Pintea A, Rugină D, Diaconeasa Z, Hanganu D, Vlase L, et al. Preliminary studies on the chemical characterisation and antioxidant capacity of polyphenols from Sambucus sp. Dig J Nanomater B1os. 2013; 8: 973-980.

[23] Kaack K, Austed T. Interaction of vitamin C and flavonoids in elderberry (Sambucus nigra L.) during juice processing. Plant Foods Hum Nutr. 1998; 52(3): 187-198.

[24] Ochmian I, Oszmiański J, Skupień K. Chemical composition, phenolics, and firmness of small black fruits. Journal of Applied Botany and Food Quality. 2009; 83: 64-69.

[25] Veberic R, Jakopič J, Stampar F, Schmitzer V. European elderberry (Sambucus nigra L.) rich in sugars, organic acids, anthocyanins and selected polyphenols. Food Chem. 2009; 114: 511-515. [CrossRef]

[26] Kaack K, Fretté XC, Christensen LP, Landbo A-K, Meyer AS. Selection of elderberry (Sambucus nigra L.) genotypes best suited for the preparation of juice. Eur Food Res Technol. 2008; 226(4): 843-855.

[27] Duymuş HG, Göger F, Başer KH. In vitro antioxidant properties and anthocyanin compositions of elderberry extracts. Food Chem. 2014; 155: 112-119. [CrossRef] 
[28] Młynarczyk K, Walkowiak-Tomczak D, Lysiak G. Bioactive properties of Sambucus nigra L. As a functional ingredient for food and pharmaceutical industry. Journal of Functional Foods. 2018; 40: 377-390. [CrossRef]

[29] Młynarczyk K, Walkowiak-Tomczak D, Staniek H, Kidoń M, Lysiak G. The content of selected minerals, bioactive compounds, and the antioxidant properties of the flowers and fruit of selected cultivars and wildly growing plants of Sambucus nigra L. Molecules. 2020; 25: 876. [CrossRef]

[30] Vlachojannis C, Zimmermann BF, Chrubasik-Hausmann S. Quantification of anthocyanins in elderberry and chokeberry dietary supplements. Phytother Res. 2015; 29(4): 561-565. [CrossRef]

[31] Krawitz C, Mraheil MA, Stein M, Imirzalioglu C, Domann E, Pleschka S, Hain T. Inhibitory activity of a standardised elderberry liquid extract against clinically-relevant human respiratory bacterial pathogens and influenza A and B viruses. BMC Compl Alternative Med. 2011; 11:16. [CrossRef]

[32] Tiralongo E, Wee SS, Lea RA. Elderberry supplementation reduces cold duration and symptoms in air-travellers: A randomised, double-blind placebo-controlled clinical trial. Nutrients. 2016; 8(4): 182. [CrossRef]

[33] Lee J, Durst RW, Wrolstad RE. Determination of total monomeric anthocyanin pigment content of fruit juices, beverages, natural colorants, and wines by the $\mathrm{pH}$ differential method: collaborative study. J AOAC Int. 2005; 88(5): $1269-1278$.

This is an open access article which is publicly available on our journal's website under Institutional Repository at http://dspace.marmara.edu.tr. 